\title{
Actinomicosis amigdalina imitando una recaída de un linfoma no Hodgkin
}

\author{
Frederico Carvalho de Medeiros y Fernando Carvalho de Medeiros
}

\footnotetext{
Hospital Santa Casa de Belo Horizonte, Minas Gerais, Brasil. Departamento de Neurología (FrCM).

Hospital Risoleta Tolentino Neves, Brasil. Departamento de Medicina Clínica (FeCM).

No existen conflictos de interés. Recibido: 7 de septiembre de 2015 Aceptado: 26 de abril de 2016

Traducción al español: 18 de julio de 2016

Correspondencia a: Frederico Carvalho de Medeiros E-mail: fredicm@bol.com.br
}

\section{Tonsillar actinomycosis mimicking relapse of diffuse large B-cell non-Hodgkin lymphoma}

We describe a case of tonsillar actinomycosis mimicking relapse of diffuse large B-cell non-Hodgkin lymphoma. Actinomycosis infection is a rare disease, clinical progression it's usually gradual and diagnoses process it's challenging. This report outlines the case of a 63-year-old woman, diagnosed with lymphoma in the right tonsil three years ago, actually in complete remission. During follow-up, there was a slight increase in lactate dehydrogenase (LDH) evaluation. Due to the possibility of a relapse of lymphoma, positron emission tomography-computed tomography (PET-CT) was performed, detecting increased activity in the left oropharynx, which appeared to be thicker in the exam. The patient was submitted to surgical excision of the lesion, with a histological diagnosis of left tonsillar actinomycosis. The genus Actinomyces is composed of non-acid-fast, anaerobic or microaerophilic, commensal bacteria of the oropharynx and the respiratory and digestive tracts. The cervicofacial form is the most common. Surgical excision is frequently essential for a definitive diagnosis. Although uncommon, it is important to include this disease in the differential diagnosis when a tumor-like mass is detected in the cervicofacial region.

Key words: Actinomycosis, Lymphoma, Tonsil, PET-CT, Head and neck.

Palabras clave: Actinomicosis, linfoma, amígdalas, PET-CT, cabeza y cuello.

\section{Introducción}

$\mathrm{L}$ a actinomicosis fue descrita por primera vez hace unos 100 años. Es una infección bacteriana, supurativa crónica, de tipo granulomatosa.

Actualmente se presenta en forma esporádica debido al amplio uso de antimicrobianos ${ }^{1}$.

El género Actinomyces está compuesto por bacterias grampositivas, de forma filamentosa, ramificada, no resistentes al ácido, anaeróbicas o microaerofílicas. Vive como un microorganismo comensal en la orofaringe, tracto respiratorio e intestinal; sin embargo, tiene la capacidad de invadir el tejido subcutáneo desde una lesión de la mucosa ${ }^{2}$.

Se puede presentar de tres formas clínicas: cérvicofacial $(50 \%)$, torácica (30\%) y abdomino-pélvica $(20 \%)^{2}$. El diagnóstico se basa en el aislamiento bacteriano en cultivos de secreciones o tejidos y en la visualización microscópica en un frotis citológico o corte histopatológico ${ }^{3}$. Debido a su capacidad invasora, el tratamiento incluye la cirugía con extirpación completa de las lesiones y la terapia complementaria con antimicrobianos. Sin embargo, no hay consenso en la duración del tratamiento ${ }^{4}$.

Comunicamos el caso clínico de una actinomicosis amigdalina que imitó una recaída de un linfoma no Hodgkin.

\section{Caso clínico}

Mujer de 63 años con antecedente de un linfoma no Hodgkin de células B grandes en la amígdala derecha hacía tres años atrás. Su tratamiento consistió en ocho dosis de rituximab, ciclofosfamida, hidroxi-daunorubicina, vincristina y prednisolona (protocolo R-CHOP) cada 21 días, por cinco meses, con remisión total de la enfermedad. En una visita de seguimiento se observó un leve aumento de la enzima lactato deshidrogenasa (LDH) 535 IU/L y $567 \mathrm{IU} / \mathrm{L}$, repetido diez días después (valor de referencia: $480 \mathrm{IU} / \mathrm{L})$. El recuento hematológico y la función renal y hepática fueron normales. No se observaron cambios relevantes en la tomografía computada (TC) de la orofarige, cuello, tórax, abdomen y pelvis. La paciente se encontraba asintomática y con un examen físico normal, con orofaringe sana, sin linfadenopatías ni hepatoesplenomegalia. Se encontraba afebril, sin pérdida de peso y sin sudoración nocturna. La paciente informó sobre la extracción de un molar derecho dos meses antes. Debido a la posibilidad de una recaída del linfoma se realizó un tomografía por emisión de positrones-tomografía computada (TEP-TC) con imágenes por fusión usando 18F-2-flúor-2-deoxi-glucosa (18F-FDG) que reveló una alta captación del radiofármaco en un área engrosada de tejido blando en la pared lateral izquierda de la orofaringe $(\mathrm{SUVmax}=10.23$ ) de contornos poco definidos (Figura 1). 


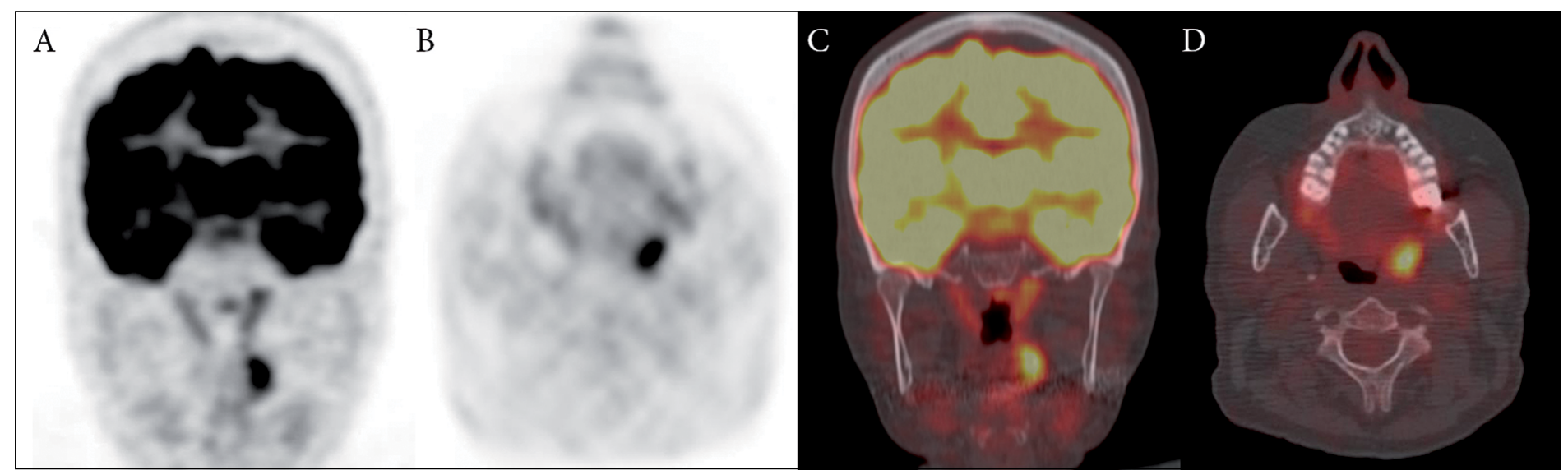

Figura 1. En TEP coronal y axial (A, B) y fusión TEP-TC (C, D) imágenes de la orofaringe, alta captación de 18F-FDG es evidente en la amígdala izquierda, sin compromiso de los ganglios linfáticos adyacentes.

La paciente fue sometida a la extirpación quirúrgica de la lesión. El examen histopatológico fue negativo para un proceso maligno. La amígdala palatina reveló una hiperplasia linfoide folicular reactiva inespecífica. La tinción de hematoxilina y eosina (40x) mostró un grupo bacteriano de forma filamentosa compatible con una actinomicosis (gránulos de azufre) (Figura 2). Se indicó tratamiento antimicrobiano con 500/125 mg de amoxicilina/ácido clavulánico, por dos meses. En el seguimiento de la paciente no se evidenciaron cambios al examen clínico, con normalización de los valores de LDH.

\section{Discusión}

La presentación cérvico-facial es la forma más común de la actinomicosis ${ }^{1,2}$. Las especies de actinomicetos presentan una baja virulencia y afectan principalmente tejido previamente dañado, en la mayoría de los casos por invasión directa ${ }^{1,3}$. Las condiciones que favorecen la infección cérvico-facial incluyen caries, extracción dental, gingivitis y trauma gingival, amigdalitis crónica, otitis, mastoiditis y trauma maxilofacial ${ }^{1-3}$. Se presenta en forma más frecuente en la región submandibular o en el ángulo mandibular, con o sin linfadenopatías cervicales ${ }^{1-3}$. También puede localizarse en la región nasofaríngea, senos paranasales, mejillas, glándulas parótidas, surco gingival, hipofaringe y amígdalas ${ }^{1,3}$. Su localización amigdalina varía entre 1,3 y $37 \%$, dependiendo del método de corte y tinción utilizado en los diferentes laboratorios ${ }^{5}$. La infección se presenta más comúnmente como una masa tumoral de crecimiento lento, dura o supurativa, que se hace visible en semanas o meses ${ }^{1,2}$. La actinomicosis cérvico-facial predomina en varones (con una relación hombre-mujer 4:1), principalmente en edades comprendidas entre los

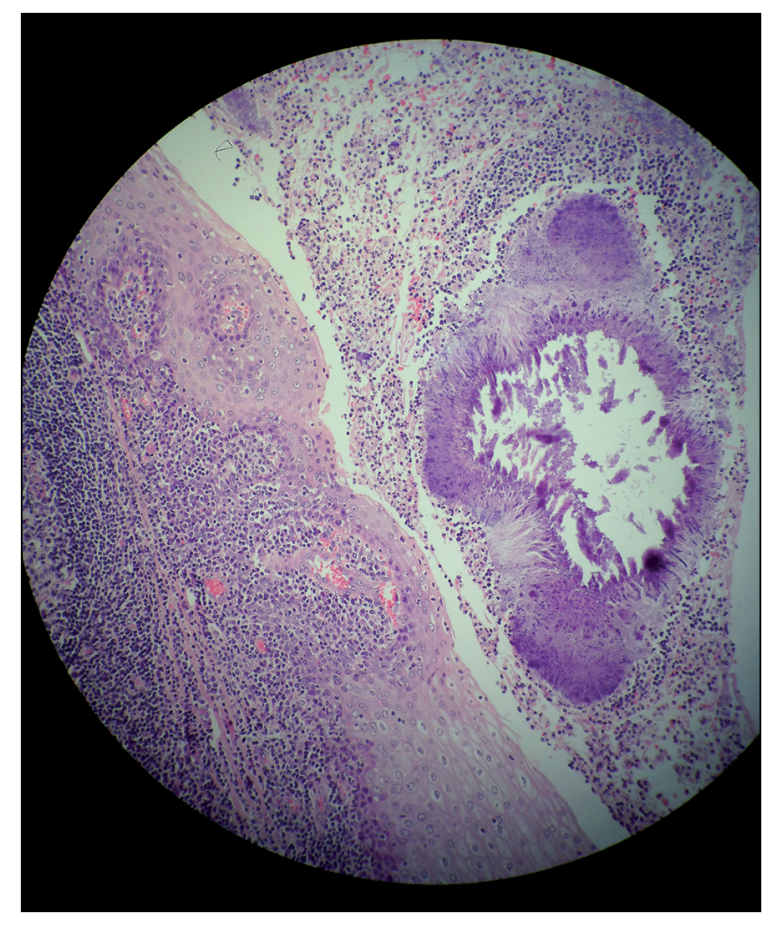

Figura 2. A la derecha de la imagen, los gránulos de azufre de Actinomyces spp. son evidentes en la amígdala. Su naturaleza filamentosa es fácilmente identificable (tinción de hematoxilina-eosina).
41 y 50 años $^{3}$. Las razones de esta predilección no son claras $^{3}$. No se ha descrito ninguna predisposición racial o geográfica ${ }^{1}$.

La presentación clínica, en general, no es específica; aunque el dolor es infrecuente. Causa fiebre en $50 \%$ de los pacientes aproximadamente, asociado a endurecimiento o eritema alrededor de la masa ${ }^{2,3}$. A medida que crece se hace más doloroso a la palpación y se adhiere a la piel que lo recubre, pudiendo aparecer congestión venosa de 
color púrpura ${ }^{2,3}$. Generalmente no existe aumento en los ganglios linfáticos regionales ${ }^{3}$. El caso clínico presentado fue completamente asintomático, lo que pudo corresponder al comienzo de un proceso infeccioso diagnosticado precozmente.

Sólo $10 \%$ de las infecciones causadas por especies del género Actinomyces son diagnosticadas después de su presentación inicial ${ }^{3}$. El diagnóstico preciso se logra mediante visualización de gránulos actinomicóticos en exudados o en secciones histopatológicas del tejido ${ }^{3}$. En cuanto al primer método, el cultivo de Actinomyces spp. es muy difícil incluso en medios anaeróbicos adecuados, y el rendimiento de cultivos positivos es inferior a $50 \%{ }^{2}$. El examen microscópico de la biopsia con tinción con hematoxilina/eosina muestra una zona exterior de granulación y una zona central de necrosis con múltiples gránulos basófilos, que representan las microcolonias lobuladas de Actinomyces spp. Actualmente, las técnicas menos invasoras han cobrado importancia, como la aspiración con aguja fina que permite una identificación morfológica comparable con el material obtenido mediante la biopsia, además de ser un medio eficaz para estudios microbiológicos ${ }^{2}$.

Las técnicas de imagenología, como tomografía computada (TC) y la resonancia magnética (RM), no proporcionan un diagnóstico específico pero ayudan a definir las dimensiones, el grado de la lesión y el compromiso del tejido subyacente, lo que es de gran ayuda para la cirugía ${ }^{2,3}$. La TC puede evidenciar un aumento de volumen de tejidos blandos con una atenuación central, asociado a cambios inflamatorios en los tejidos adyacentes ${ }^{6}$. La granulación abundante y atenuación de los tejidos fibrosos en la masa pueden producir una captación de alto contraste, mientras que la necrosis supurativa central puede dificultar la captación de contraste ${ }^{6}$. Las imágenes de la RM T1 y T2 ponderadas, muestran una intensidad de señal intermedia asociada a una captación de contraste moderada $^{6}$. En este caso, la ausencia de cambios en la TC fue otro factor que sugería un proceso infeccioso.

En cuanto a las dificultades de diagnóstico, la actinomicosis cérvico-facial puede simular otras lesiones granulomatosas crónicas, como la tuberculosis, infecciones micóticas y neoplasias malignas de cabeza y cuello ${ }^{6}$. La neoplasia maligna puede resultar en un aumento de la masa sólida, pero habitualmente, la lesión tiene márgenes bien definidos, sin cambios inflamatorios importantes en los tejidos adyacentes ${ }^{6}$.

En la literatura científica se encuentran cinco casos bien descritos de actinomicosis asociada al linfoma noHodgkin $^{7-10}$; sin embargo, en nuestro conocimiento éste es el primer caso con compromiso amigdalino, imitando una recaída del linfoma. No fue posible determinar una relación precisa entre las dos patologías. Mucho se ha discutido en cuanto a la inmunosupresión por causa del cáncer y de su tratamiento como factor predisponente en el desarrollo de infecciones bacterianas ${ }^{7,9}$. En nuestro caso, la paciente no presentó síntomas clínicos o parámetros de laboratorio inflamatorios secundarios a la actinomicosis. Es poco probable que la infección se debió a un estado de inmunosupresión causado por el linfoma; más bien, estuvo probablemente relacionada con el antecedente de la extracción molar. De acuerdo con la historia clínica de la paciente, la hipótesis más razonable era una recaída de su linfoma, y teniendo en cuenta su presentación asintomática, un diagnóstico primario de actinomicosis habría sido bastante inusual. Por consiguiente, se realizó un TEP-TC que mostró una alta captación del 18F-FDG en la amígdala izquierda sin ganglios linfáticos adyacentes reactivos. Aunque este es un marcador muy sensible, no es un radiotrazador específico de infección ${ }^{11}$. Son pocos los casos documentados de actinomicosis detectada por este radio-fármaco ${ }^{11}$.

El FDG puede ser útil para distinguir entre lesiones benignas y malignas, ya que la evidencia de malignidad tiene generalmente una tasa glucolítica más alta y por consiguiente mayor captación del FDG ${ }^{12}$. Algunos usan el umbral máximo del valor de captación estandarizado (SUV) de 2,5 para distinguirlos ${ }^{12}$. Sin embargo, las mediciones SUV dependen de varios parámetros: equipo utilizado, la física (scanner de variabilidad, cambios de parámetros de reconstrucción, error de calibración entre el scanner y calibrador de dosis, desfase entre scanner y calibrador de dosis, uso de material de contraste en TEP/TC, variabilidad interobservador) y factores biológicos (composición de peso, medición de tamaño corporal, corrección de glucosa en la sangre, equipo de captación post inyección, movimiento respiratorio) ${ }^{12,13}$. Además, los procesos infecciosos e inflamatorios pueden conducir a un aumento de captación del FDG mucho mayor que el SUV 2,5, principalmente en lesiones infecciosas agudas ${ }^{12,13}$. Debido a tantas variables, un SUV mayor de 2,5 no debe ser decisivo para diferenciar entre lesiones benignas y malignas ${ }^{12}$. Por consiguiente, debe ser necesario un estudio histopatologico para confirmar el diagnóstico.

El tratamiento es individualizado, por lo que la duración de la terapia con antimicrobianos dependerá del lugar y grado de avance de la infección, y la respuesta clínica e imagenológica ${ }^{3}$. La penicilina sigue siendo el antibacteriano de preferencia, comenzando con la administración intravenosa hasta obtener una mejoría clínica y posteriormente con terapia oral ${ }^{4}$. Puede o no asociarse metronidazol, que hace el medio desfavorable para Actinomyces spp. Amoxicilina/ácido clavulánico es otra opción descrita ${ }^{4}$. Para pacientes alérgicos a penicilina, son alternativas doxiciclina, minociclina, tetraciclina, clindamicina, eritromicina y cefalosporinas ${ }^{14}$. Las tetraciclinas son probablemente la mejor opción ${ }^{3}$. No hay consenso en 
la duración del tratamiento, el que puede variar de tres a 52 semanas $^{4}$. En general, la cirugía combinada con la terapia antimicrobiana es efectiva ${ }^{4}$.

Siempre se debe indicar el drenaje quirúrgico de los abscesos $^{3}$. Cabe resaltar que la cirugía (biopsia excisional) también se utiliza para el diagnóstico definitivo en la mayoría de los casos, lo que optimiza el tratamiento, como se pudo comprobar en nuestro paciente. Optamos por la cirugía, complementada con dos meses de terapia antibacteriana (amoxicilina/ácido clavulánico), a fin de prevenir la recurrencia de la infección.

La actinomicosis cérvico-facial generalmente tiene un buen pronóstico, con una mejoría completa en más de $90 \%$ de los pacientes tratados con antimicrobianos ${ }^{3}$. El resultado tiende a ser mejor cuando se combina con cirugía.

Agradecimientos. Nuestros agradecimientos a João Lucas Breder y Livia Caroline da Silva por su ayuda en la preparación de las cifras.

\section{Resumen}

La actinomicosis es una infección poco frecuente, lentamente progresiva y de difícil diagnóstico. Se presenta el caso clínico de una mujer de 63 años en remisión total de un linfoma no Hodgkin difuso de células B grandes de amígdala. Durante su seguimiento se observó un ligero aumento de la lactato deshidrogenasa (LDH). Por la posibilidad de una recaída de su linfoma se realizó una tomografía por emisión de positrones (TEP-TC) que detectó mayor densidad y actividad en la orofaringe izquierda. Se realizó la extirpación de la lesión, cuyo diagnóstico histopatológico fue de una actinomicosis amigdalina. El género Actinomyces es comensal de la orofaringe y de la vía respiratoria y digestiva. La forma cérvico-facial es la más frecuente. La extirpación quirúrgica es a menudo esencial para un diagnóstico definitivo. Es importante incluir esta enfermedad en el diagnóstico diferencial de las lesiones tumorales de la región cérvico-facial.

\section{Referencias bibliográficas}

1.- Lancella A, Abbate G, Foscolo A M, Dosdegani R. Two unusual presentations of cervicofacial actinomycosis and review of the literature. Acta Otorhinolaryngol Ital 2008; 28 : 89-93.

2.- Volante M, Contucci A M, Fantoni M, Ricci R, Galli J. Cervicofacial actinomycosis: still a difficult differential diagnosis. Acta Otorhinolaryngol Ital 2005; 25: 116-9.

3.- Oostman O, Smego R A. Cervicofacial actinomycosis: diagnosis and management. Curr Infect Dis Rep 2005; 7: 170-4.

4.- Moghimi M, Salentijn E, Debets-Ossenkop Y, Karagozoglu K, Forouzanfar T. Treatment of cervicofacial actinomycosis: a report of 19 cases and review of literature. Med Oral Patol Oral Cir Bucal 2013; 18: e627-32.

5.- $\quad$ Samant S, Sandoe J, High A, Makura Z G. Actinomycosis mimicking a tonsillar neoplasm in an elderly diabetic patient. Br J Oral Maxillofac Surg 2009; 47: 417-8.

6.- Park J K, Lee H K, Ha H K, Choi H Y, Choi C G. Cervicofacial actinomycosis: $\mathrm{CT}$ and MR imaging findings in seven patients. AJNR Am J Neuroradiol 2003; 24: 331-5.

7.- Guerci A P, Merle-Melet M, Mory F, Blum A, Floquet J, Deneuville M, et al. Actinomycose et lymphoma malin non hodgkinien: association fortuite? Rev Med Interne 1996; 17: 571-5.

8.- Dentale N, Fulgaro C, Fasulo G, Guerra L, Legnani G, Mazzetti M, et al. Cervicofacial and pulmonary actinomycosis associated with nonHodgkin's lymphoma. Scand J Infect Dis 1998; 30: 519-20.

9.- Batt J A, Mullen J B, Vellend H, Balter M S. Thoracic actinomycosis in a patient with pulmonary involvement caused by nonHodgkin's lymphoma. Clin Infect Dis 1996; 22: 731-2.

10.- Winter R J, Hoffbrand B I, Souhami R L.
Simultaneous occurrence of actinomycosis and lymphocytic lymphoma. J R Soc Med 1983; 76: 1071-2.

11.- Singla S, Singh H, Mukherjee A, Karunanithi S, Bal C, Kumar R. Cervical and thoracic actinomycosis on 18F-FDG PET/CT. Clin Nucl Med 2014; 39: 623-4.

12.- Kwee T C, Cheng G, Lam M G, Basu S, Alavi A. SUVmax of 2.5 should not be embraced as a magic threshold for separating benign from malignant lesions. Eur J Nucl Med Mol Imaging 2013; 40: 1475-7.

13.- Adams M C, Turkington T G, Wilson J M, Wong T Z. A systematic review of the factors affecting accuracy of SUV measurements. AJR Am J Roentgenol 2010; 195: 310-20.

14.- Acevedo F, Baudrand R, Letelier L M, Gaete P. Actinomycosis: a great pretender. Case reports of unusual presentations and a review of the literature. Int J Infect Dis 2008; 12: 358-62. 